\title{
A novel AKT3 mutation in melanoma tumours and cell lines
}

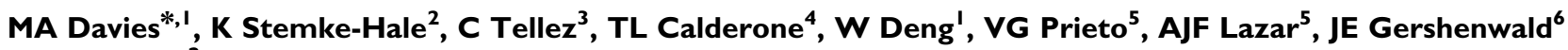 \\ and GB Mills ${ }^{2}$
}

'Department of Melanoma Medical Oncology, The University of Texas MD Anderson Cancer Center, 1515 Holcombe Blvd, Houston, TX 77030, USA; ${ }^{2}$ Department of Systems Biology, The University of Texas MD Anderson Cancer Center, 1515 Holcombe Blvd, Houston, TX 77030, USA; ${ }^{3}$ Molecular Biology and Lung Cancer Program, Lovelace Respiratory Research Institute, 2425 Ridgecrest Dr SE, Albuquerque, NM 87I08, USA; ${ }^{4}$ Department of Surgical Oncology, The University of Texas M D Anderson Cancer Center, 1515 Holcombe Blvd, Houston, TX 77030, USA; ${ }^{5}$ Department of Pathology, The University of Texas MD Anderson Cancer Center, I 515 Holcombe Blvd, Houston, TX 77030, USA; ${ }^{6}$ Department of Surgical Oncology and Cancer biology, The University of Texas MD Anderson Cancer Center, 1515 Holcombe Blvd, Houston, TX 77030, USA

Recently, a rare activating mutation of AKTI (EI TK) has been reported in breast, ovarian, and colorectal cancers. However, analogous activating mutations in AKT2 or AKT3 have not been identified in any cancer lineage. To determine the prevalence of AKT EI7K mutations in melanoma, the most aggressive form of skin cancer, we analysed 137 human melanoma specimens and 65 human melanoma cell lines for the previously described activating mutation of AKTI, and for analogous mutations in AKT2 and AKT3. We identified a single AKTI E I 7K mutation. Remarkably, a previously unidentified AKT3 E I 7K mutation was detected in two melanomas (from one patient) as well as two cell lines. The AKT3 EI7K mutation results in activation of AKT when expressed in human melanoma cells. This represents the first report of AKT mutations in melanoma, and the initial identification of an AKT3 mutation in any human cancer lineage. We have also identified the first known human cell lines with naturally occurring AKT E I 7K mutations. British Journal of Cancer (2008) 99, 1265-1268. doi: I0.I038/sj.bjc.6604637 www.bjcancer.com

Published online 23 September 2008

(c) 2008 Cancer Research UK

Keywords: AKT; mutation; melanoma

Melanoma is the most aggressive form of skin cancer, and patients with metastatic disease have a dismal prognosis that is not significantly improved with systemic therapies (Tsao et al, 2004). The pattern of genetic alterations in this disease suggests that activation of kinase signalling pathways has an important function in the initiation and pathophysiology of melanoma. $B R A F$, a serinethreonine kinase in the RAS/RAF/MAPK signalling cascade, is mutated in $60-70 \%$ of melanomas and, to date, represents the most common mutation in this disease (Davies et al, 2002; Curtin et al, $2005)$. Over $80 \%$ of the $B R A F$ mutations involve a missense mutation that results in the substitution of glutamic acid for valine at amino acid 600 (V600E). Expression of this mutant form of BRAF in vitro results in constitutive activation of MAPK (Davies et al, 2002). The PI3K/AKT pathway may also have an important function in melanoma. NRAS, which activates both the RAS/RAF/MAPK and the PI3K/AKT signalling pathways, is mutated in approximately $15 \%$ of melanoma tumours and cell lines (Goydos et al, 2005; Goel et al, 2006). Loss of function of the tumour suppressor PTEN, which results in activation of the PI3K/AKT pathway, occurs in $10-30 \%$ of melanomas, frequently concurrent with activating $B R A F$ mutations (Tsao et al, 1998; Zhou et al, 2000; Haluska et al, 2006). Activating mutations of PIK3CA, which encodes the p110 $\alpha$ catalytic subunit of PI3Ks, have been detected with significant frequency in colon, breast, and ovarian cancers, but appear to be rare in melanoma $(1.5 \%)$ (Curtin et al, 2006; Omholt et al, 2006).

$\mathrm{AKT} / \mathrm{PKB}$, a serine-threonine kinase, is a key downstream effector of PI3K-mediated signalling (Downward, 2004). Recently,

*Correspondence: Dr MA Davies; E-mail: mdavies@mdanderson.org Received 13 May 2008; revised 18 July 2008; accepted 4 August 2008; published online 23 September 2008 a point mutation in $A K T 1$ was identified in breast, ovarian, and colon cancers (Carpten et al, 2007). This mutation (E17K) increases recruitment of AKT1 to the membrane, increases AKT1 phosphorylation and activity, transforms Rat1 fibroblasts, and induces leukaemia in transgenic mice (Carpten et al, 2007). No melanoma specimens were examined in that study. To determine whether $A K T E 17 K$ mutations occur in melanoma, we used a mass spectroscopy-based approach designed to detect single-nucleotide polymorphisms (SNPs) to determine the frequency of this activating mutation in $A K T 1, A K T 2$, and $A K T 3$ isoforms in a large panel of human melanoma specimens and human cell lines.

\section{MATERIALS AND METHODS}

\section{Clinical specimens}

The OCT-embedded frozen clinical specimens were obtained from the Melanoma Informatics, Tissue Resource and Pathology Core at The University of Texas MD Anderson Cancer Center under an Institutional Review Board approved protocol (PI- JEG). The H\&E slides were reviewed by an experienced dermatopathologist (VGP or AJFL) to identify specimens with regions enriched for viable tumour cells. These slides were used as a guide to macrodissect the OCT block and isolate the selected tumour-enriched region. Ten- to twenty-micrometre shears were prepared at $-20^{\circ} \mathrm{C}$ and then were stored at $-80^{\circ} \mathrm{C}$ for molecular studies. An additional $\mathrm{H} \& \mathrm{E}$ slide was made after all shears were prepared and was reviewed by an experienced dermatopathologist to confirm $>70 \%$ tumour content in the section used. Genomic DNA was isolated using the QIAmp DNA Mini kit (Qiagen, Valencia, CA, USA) according to the manufacturer's guidelines. 


\section{Cell lines}

Human melanoma cell lines were grown under normal tissue culture conditions in RPMI supplemented with fetal calf serum. Cell pellets were isolated, and DNA was extracted using the QIAmp DNA Mini kit (Qiagen) according to the manufacturer's guidelines.

\section{Mass spectroscopy-based $A K T$ mutation detection}

A mass spectroscopy-based approach evaluating SNPs was used to detect the AKT1 E17K mutation, and mutations in the equivalent sites of $A K T 2$ and AKT3 (Thomas et al, 2007). Polymerase chain reaction (PCR) and extension primers for $A K T 1, A K T 2$, and $A K T 3$ were designed using Sequenom Inc. (San Diego, CA, USA) Assay Design. PCR-amplified DNA was cleaned using EXO-SAP (Sequenom), primer extended by IPLEX chemistry, desalted using Clean Resin (Sequenom), and spotted onto Spectrochip matrix chips using a nanodispenser (Samsung). Chips were run in duplicate on a Sequenom MassArray MALDI-TOF MassArray system. Sequenom Typer Software and visual inspection were used to interpret mass spectra. Reactions where more than $15 \%$ of the resultant mass ran in the mutant site in both reactions were scored as positive. All mutations were confirmed by Sanger sequencing in the MD Anderson Cancer Center Support Grant-supported sequencing core.

\section{Plasmids}

Human AKT3 cDNA cloned into the pcDNA3 vector with a HA-tag at the N-terminus was generously provided by Dr Yiling Lu (MD Anderson Cancer Center). The $\mathrm{G} \rightarrow \mathrm{A}$ point mutation that results in the substitution of lysine for glutamic acid at amino acid 17 was introduced using Quick-Change Site-Directed Mutagenesis (Stratagene, La Jolla, CA, USA). The nucleotide change was confirmed by direct sequencing.

\section{Transient transfection and western blotting}

The A375 human melanoma cell line was seeded the day before transfection on six-well tissue culture plates. Cells were transfected with indicated plasmids and Fugene HD Transfection Reagent (Roche, Indianapolis, IN, USA) as per the manufacturer's instructions. Eight hours after transfection the media was replaced. After $48 \mathrm{~h}$ transfection, media was replaced with media containing either 5 or $0 \%$ serum ('Serum-free'). Twenty-four hours later the cells were harvested, washed with PBS, and resuspended in lysis buffer containing $1 \%$ Triton X-100, $50 \mathrm{~mm}$ HEPES, $\mathrm{pH}$ 7.4, $150 \mathrm{~mm}$ $\mathrm{NaCl}, 1.5 \mathrm{~mm} \mathrm{MgCl}_{2}, 1 \mathrm{~mm}$ EGTA, $100 \mathrm{~mm} \mathrm{NaF}, 10 \mathrm{~mm} \mathrm{Na}$ pyrophosphate, $1 \mathrm{~mm} \mathrm{Na} \mathrm{VO}_{4}, 10 \%$ glycerol, and supplemented with complete Protease Inhibitor Cocktail tablet (Roche). Protein isolation and western blotting were performed using the standard techniques (Hennessy et al, 2007). Antibodies against HA tag (Covance, Princeton, NJ, USA), Phospho-AKT Ser473 (C terminus), Phospho-AKT Thr308 (activation loop), and AKT3 (Cell Signaling Technology, Danvers, MA, USA) were used. The Phospho-AKT antibodies, which are designated above by the relevant residues in $\mathrm{AKT} 1$, also recognise the corresponding residues in AKT2 (Ser474, Thr309) and AKT3 (Ser472, Thr305).

\section{RESULTS}

\section{Detection of $A K T 1 E 17 K$ and $A K T 3 E 17 K$ mutations in melanoma}

We analysed melanoma clinical specimens for the presence of mutations in $A K T 1, A K T 2$, and $A K T 3$ that result in the $E 17 K$ mutation identified previously in breast, ovarian, and colorectal cancers. We used mass spectroscopy-based mutation detection, which previously has been demonstrated to be a sensitive method for detecting specific point mutations in clinical specimens and cell lines (Thomas et al, 2007). Genomic DNA was analysed from 137 clinical specimens. Specimens were primarily from metastatic lesions, including soft tissue $(n=16)$, lymph nodes $(n=77)$, and parenchymal metastases $(n=28)$; primary melanomas $(n=16)$ were also analysed. We identified two lymph node metastases (from a single patient) that had the AKT3 E17K mutation (Figure 1A). This mutation was not present in the DNA from normal tissue of the same patient (Supplementary Figure 1). One lymph node metastasis from a different patient harboured the AKT1 E17K mutation. The AKT3 and AKT1E17K mutations were confirmed by conventional Sanger sequencing (Figure $1 \mathrm{~B}$, and Supplementary Figure 2).

We performed a similar analysis on genomic DNA isolated from 65 human melanoma cell lines (Supplementary Figure 3). We did not identify any cell lines with AKT1 E17K or AKT2 E17K mutations. However, we identified two cell lines with AKT3 E17K mutations, WM46 and D40. Both cell lines were derived from metastatic lesions. It is unlikely that these cell lines were crosscontaminated or originated from the same patient, as they were derived in laboratories in different hemispheres, and the cell lines differed in the genetic sequences for other genes, including $M C 1 R$ and CDK4 (MAD and KS-H, unpublished data) (Landi et al, 2006).

\section{Activation of AKT3 by the E17K mutation}

Previous studies demonstrated that expression of AKT1 E17K protein in NIH 3T3 cells increased AKT phosphorylation in those cells (Carpten et al, 2007). To determine whether the AKT3 E17K mutation results in a similar phenotype, we generated mammalian expression vectors with HA-tag-fused $A K T 3$ (wild type) and HA-tag-fused $A K T 3 E 17 K$. These vectors, as well as empty control vector, were transiently transfected in the A375 human melanoma cell line. The A375 cell line was derived from a lymph node metastasis, the same anatomic setting as the specimens that harboured the AKT3 E17K mutation(Kozlowski et al, 1984). The A375 cells do not have an activating mutation of $A K T$, PIK3CA, or $\mathrm{N}$-ras, and express PTEN protein (MAD and KS-H, unpublished data). Expression of AKT3 E17K in A375 cells increased AKT phosphorylation, as compared to transfection with the control vectors or wild-type AKT3, under normal tissue culture conditions (Figure 1, Panel C). Similar results were also seen when the cells were grown in the absence of growth factors (Supplementary Figure 4).

\section{DISCUSSION}

The PI3K signalling pathway is a critical regulator of many cellular processes that contribute to the aggressive nature of cancer, including proliferation, survival, invasion, and angiogenesis (Hennessy et al, 2005). We sought to determine if the recently identified activating mutation $(E 17 K)$ in $A K T 1$, which was initially detected in breast, colorectal, and ovarian cancers, and more recently in lung cancer, occurs in melanoma tumours and cell lines (Carpten et al, 2007; Kim et al, 2008; Malanga et al, 2008). In this study, we identified the same AKT1 E17K mutation reported previously in other cancers in the tumour from a melanoma patient. We also identified the analogous E17K mutation in AKT3 in two different tumours (from the same patient) and in two human melanoma cell lines. Two previous studies failed to detect AKT3 mutations in clinical specimens of breast $(n=154)$, colorectal $(n=155)$, ovarian $(n=50)$, gastric $(n=180)$, hepatocellular carcinoma $(n=68)$, non-small cell lung cancer $(n=157)$, and adult acute leukaemias $(n=129)$ (Carpten et al, 2007; Kim et al, 2008). We have analysed an additional 547 primary breast cancers without detecting $A K T 2$ or AKT3 E17K mutations (Stemke-Hale 


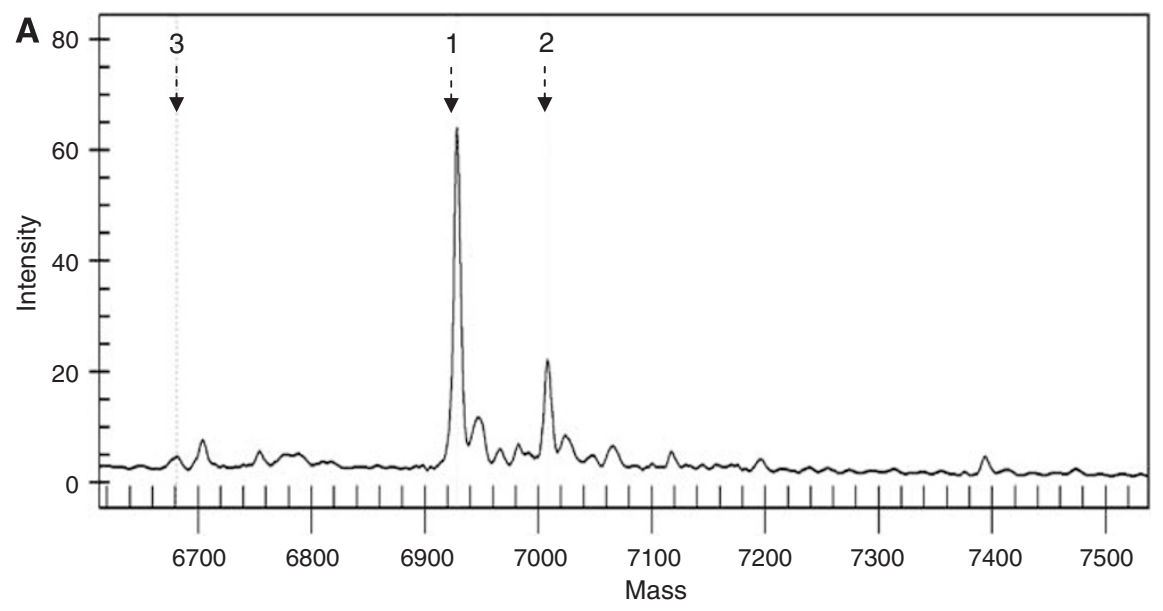

B

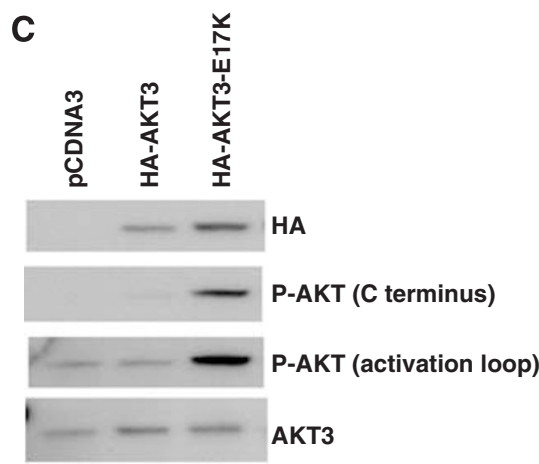

Figure I AKT3 EI7K mutation in melanoma. (A) Mass spectroscopy-based detection of AKT3 E / 7K mutation in a human melanoma clinical specimen. Peaks correlating with wild-type AKT3 ('I') and mutant AKT3 ('2') are indicated. ('3' = predicted mass of unincorporated primer). Only the wild-type peak was seen in normal tissue from the same patient (Supplementary Figure I). (B) Confirmatory Sanger sequencing of tumour analysed by mass spectroscopybased method in $(\mathbf{A})$. The missense substitution resulting in the E I7K mutation is indicated with an arrow. (C) Western blotting analysis of A375 human melanoma cells transfected with empty control vector ('PcDNA3'), HA-tagged wild-type AKT3 ('HA-AKT3'), and HA-tagged mutant AKT3 ('HA-AKT3 EI7K'). Results shown are for cells growing under normal tissue culture conditions.

et al, 2008). Thus, this study represents the first report of an AKT3 mutation in human cancer.

Normal tissue from the patient with the AKT3 E17K mutation failed to show evidence of this mutation (Supplementary Figure 1). Thus, it is likely that the mutation was somatically acquired and was not present in the germline. Unfortunately, DNA was not available from the primary tumour of this patient, so it is unknown if the mutation was present only in metastases. Of note, in both of the tumour samples from this patient the observed prevalence of the AKT3 E17K mutation was $\sim 30 \%$ (Figure $1 \mathrm{~A}$ ), meaning that $\sim 60 \%$ of the analysed cells harbour the mutation if it is heterozygous. Visual review by an experienced dermatopathologist (AJFL) of H\&E slides of these samples determined that the percentage of tumour cells in the specimens was close to $80 \%$. It could be that only a portion of the tumour cells had the AKT3 mutation. Another explanation is that the lower percentage of tumour cells could be because of smaller infiltrating lymphocytes or other contaminating non-tumour cells that were in the deeper cuts used to extract DNA but not readily apparent in the H\&E stain. Alternatively, the reason might be technical differences due to PCR amplification biases or because higher mass ions are discriminated against each other.

The discovery of an AKT3 mutation in melanoma is consistent with previous data that suggest that this isoform of $A K T$ may be particularly critical in this cancer. Stahl et al (2004) found that AKT3 protein, but not AKT1 or AKT2 protein, was increased in melanoma cell lines when compared to normal melanocytes. Transfection of siRNA against each AKT isoform in three different melanoma cell lines demonstrated that the AKT3 isoform was responsible for the majority of phosphorylated AKT in those cells (Stahl et al, 2004). While previous studies of small numbers of melanomas ( $n=20$ and $n=16$, respectively) failed to identify mutations in AKT (Waldmann et al, 2001, 2002), copy-number increases of the region of chromosome 1 where AKT3 is located have been reported (Thompson et al, 1995; Bastian et al, 2000; Curtin et al, 2005).

It will be important to determine the functional significance of the AKT3 E17K mutation. Preclinical models have demonstrated that the isoforms of $A K T$ may have markedly different effects on cellular behaviours, including invasiveness and metastatic potential (Hutchinson et al, 2004; Irie et al, 2005). Others have demonstrated that although AKT1, AKT2, and AKT3 have several shared substrates, there are also proteins that are selectively regulated by individual isoforms (Brognard et al, 2007). A critical finding in the data presented here is the identification of two human cancer cell lines with the AKT3 E17K mutation. To date, we have tested a total of 178 human cancer cell lines for AKT E17K mutations, including the entire NCI60 cell line collection, as well as additional breast $(n=41)$ and ovarian $(n=27)$ cancer cell lines (KS-H, not presented). WM46 and D40 were the only cell lines found to harbour the $E 17 \mathrm{~K}$ mutation in any $A K T$ isoforms, and to our knowledge are the first human cell lines identified with any $A K T$ mutation. These cell lines can be utilised to examine the function of the AKT3 E17K mutant protein in a cellular setting in which physiologically relevant compensatory changes have occurred. 


\section{ACKNOWLEDGEMENTS}

Support for these studies was provided by Grant P50 CA93459 from the MD Anderson Cancer Center SPORE in Melanoma, the Kleberg Center for Molecular Markers, CCSG P30 CA16672, and the Grossman Foundation for Melanoma Research. We acknowledge the following collaborators for generously donating cell lines for use in this study: Meenhard Herlyn (Wistar Institute, Philadelphia, PA, USA); Elizabeth Grimm (University of TexasMD Anderson Cancer Center, Houston, TX, USA); Nicholas Hayward, Christopher Schmidt, and Peter Parsons (Queensland
Institute of Medical Research, Herston, QZ, USA). The melanoma cell lines in the NCI60 were obtained through a collaboration with the National Cancer Institute and were provided by Susan Holbeck (NCI, Bethesda, MD, USA). MAD was supported by The ASCO Cancer Foundation Young Investigator Award. Any opinions, findings, and conclusions expressed in this material are those of the author(s) and do not necessarily reflect those of the American Society of Clinical Oncology or The ASCO Cancer Foundation.

Supplementary Information accompanies the paper on British Journal of Cancer website (http://www.nature.com/bjc)

\section{REFERENCES}

Bastian BC, Kashani-Sabet M, Hamm H, Godfrey T, Moore II DH, Brocker EB, LeBoit PE, Pinkel D (2000) Gene amplifications characterize acral melanoma and permit the detection of occult tumor cells in the surrounding skin. Cancer Res 60: 1968-1973

Brognard J, Sierecki E, Gao T, Newton AC (2007) PHLPP and a second isoform, PHLPP2, differentially attenuate the amplitude of Akt signaling by regulating distinct Akt isoforms. Molecular Cell 25: 917-931

Carpten JD, Faber AL, Horn C, Donoho GP, Briggs SL, Robbins CM, Hostetter G, Boguslawski S, Moses TY, Savage S, Uhlik M, Lin A, Du J, Qian YW, Zeckner DJ, Tucker-Kellogg G, Touchman J, Patel K, Mousses S, Bittner M, Schevitz R, Lai MH, Blanchard KL, Thomas JE (2007) A transforming mutation in the pleckstrin homology domain of AKT1 in cancer. Nature 448: 439 - 444

Curtin JA, Fridlyand J, Kageshita T, Patel HN, Busam KJ, Kutzner H, Cho KH, Aiba S, Brocker EB, LeBoit PE, Pinkel D, Bastian BC (2005) Distinct sets of genetic alterations in melanoma. $N$ Engl J Med 353: 2135-2147

Curtin JA, Stark MS, Pinkel D, Hayward NK, Bastian BC (2006) PI3-kinase subunits are infrequent somatic targets in melanoma. J Invest Dermatol 126: $1660-1663$

Davies H, Bignell GR, Cox C, Stephens P, Edkins S, Clegg S, Teague J, Woffendin H, Garnett MJ, Bottomley W, Davis N, Dicks E, Ewing R, Floyd Y, Gray K, Hall S, Hawes R, Hughes J, Kosmidou V, Menzies A, Mould C, Parker A, Stevens C, Watt S, Hooper S, Wilson R, Jayatilake H, Gusterson BA, Cooper C, Shipley J, Hargrave D, Pritchard-Jones K, Maitland N, Chenevix-Trench G, Riggins GJ, Bigner DD, Palmieri G, Cossu A, Flanagan A, Nicholson A, Ho JW, Leung SY, Yuen ST, Weber BL, Seigler HF, Darrow TL, Paterson H, Marais R, Marshall CJ, Wooster R, Stratton MR, Futreal PA (2002) Mutations of the BRAF gene in human cancer. Nature 417: $949-954$

Downward J (2004) PI 3-kinase, Akt and cell survival. Semin Cell Dev Biol 15: $177-182$

Goel VK, Lazar AJ, Warneke CL, Redston MS, Haluska FG (2006) Examination of mutations in BRAF, NRAS, and PTEN in primary cutaneous melanoma. J Invest Dermatol 126: 154-160

Goydos JS, Mann B, Kim HJ, Gabriel EM, Alsina J, Germino FJ, Shih W, Gorski DH (2005) Detection of B-RAF and N-RAS mutations in human melanoma. J Am Coll Surg 200: $362-370$

Haluska FG, Tsao H, Wu H, Haluska FS, Lazar A, Goel V (2006) Genetic alterations in signaling pathways in melanoma. Clin Cancer Res 12: 2301s-2307s

Hennessy BT, Lu Y, Poradosu E, Yu Q, Yu S, Hall H, Carey MS, Ravoori M, Gonzalez-Angulo AM, Birch R, Henderson IC, Kundra V, Mills GB (2007) Pharmacodynamic markers of perifosine efficacy. Clin Cancer Res 13: $7421-7431$

Hennessy BT, Smith DL, Ram PT, Lu Y, Mills GB (2005) Exploiting the PI3K/AKT pathway for cancer drug discovery. Nat Rev Drug Discov 4: 988- 1004

Hutchinson JN, Jin J, Cardiff RD, Woodgett JR, Muller WJ (2004) Activation of Akt-1 (PKB-\{alpha\}) Can Accelerate ErbB-2-Mediated Mammary Tumorigenesis but Suppresses Tumor Invasion. Cancer Res 64: $3171-3178$

Irie HY, Pearline RV, Grueneberg D, Hsia M, Ravichandran P, Kothari N, Natesan S, Brugge JS (2005) Distinct roles of Akt1 and Akt2 in regulating cell migration and epithelial-mesenchymal transition. J Cell Biol 171: $1023-1034$
Kim MS, Jeong EG, Yoo NJ, Lee SH (2008) Mutational analysis of oncogenic AKT E17K mutation in common solid cancers and acute leukaemias. $\mathrm{Br} \mathrm{J}$ Cancer 98(9): $1533-1535$

Kozlowski JM, Hart IR, Fidler IJ, Hanna N (1984) A human melanoma line heterogeneous with respect to metastatic capacity in athymic nude mice. J Natl Cancer Inst 72: 913-917

Landi MT, Bauer J, Pfeiffer RM, Elder DE, Hulley B, Minghetti P, Calista D, Kanetsky PA, Pinkel D, Bastian BC (2006) MC1R germline variants confer risk for BRAF-mutant melanoma. Science 313: $521-522$

Malanga D, Scrima M, De Marco C, Fabiani F, De Rosa N, De Gisi S, Malara N, Savino R, Rocco G, Chiappetta G, Franco R, Tirino V, Pirozzi G, Viglietto $G$ (2008) Activating E17K mutation in the gene encoding the protein kinase AKT1 in a subset of squamous cell carcinoma of the lung. Cell Cycle 7: 665-669

Omholt K, Krockel D, Ringborg U, Hansson J (2006) Mutations of PIK3CA are rare in cutaneous melanoma. Melanoma Res 16: 197-200

Stahl JM, Sharma A, Cheung M, Zimmerman M, Cheng JQ, Bosenberg MW Kester M, Sandirasegarane L, Robertson GP (2004) Deregulated Akt3 activity promotes development of malignant melanoma. Cancer Res 64: $7002-7010$

Stemke-Hale K, Gonzalez-Angulo AM, Lluch A, Neve RM, Davies MA, Carey M, Sahin A, Symmans WF, Pusztai L, Nolden LK, Horlings H, Berns K, Hung M-C, Van de Vijver M, Valero V, Gray JW, Bernards R, Mills GB, Hennessy BT (2008) An integrative genomic and proteomic analysis of PIK3CA, PTEN, and AKT mutations in breast cancer. Cancer Res 68(15): 6084-6091

Thomas RK, Baker AC, Debiasi RM, Winckler W, Laframboise T, Lin WM, Wang M, Feng W, Zander T, Macconnaill LE, Lee JC, Nicoletti R, Hatton C, Goyette M, Girard L, Majmudar K, Ziaugra L, Wong KK, Gabriel S, Beroukhim R, Peyton M, Barretina J, Dutt A, Emery C, Greulich H, Shah K, Sasaki H, Gazdar A, Minna J, Armstrong SA, Mellinghoff IK, Hodi FS, Dranoff G, Mischel PS, Cloughesy TF, Nelson SF, Liau LM, Mertz K, Rubin MA, Moch H, Loda M, Catalona W, Fletcher J, Signoretti S, Kaye F, Anderson KC, Demetri GD, Dummer R, Wagner S, Herlyn M, Sellers WR, Meyerson M, Garraway LA (2007) High-throughput oncogene mutation profiling in human cancer. Nat Genet 39: 347-351

Thompson FH, Emerson J, Olson S, Weinstein R, Leavitt SA, Leong SP, Emerson S, Trent JM, Nelson MA, Salmon SE, Taetle R (1995) Cytogenetics of 158 patients with regional or disseminated melanoma. Subset analysis of near-diploid and simple karyotypes. Cancer Genet Cytogenet 83: $93-104$

Tsao H, Atkins MB, Sober AJ (2004) Management of cutaneous melanoma. $N$ Engl J Med 351: $998-1012$

Tsao H, Zhang X, Benoit E, Haluska FG (1998) Identification of PTEN/ MMAC1 alterations in uncultured melanomas and melanoma cell lines. Oncogene 16: $3397-3402$

Waldmann V, Wacker J, Deichmann M (2001) Mutations of the activationassociated phosphorylation sites at codons 308 and 473 of protein kinase $\mathrm{B}$ are absent in human melanoma. Arch Dermatol Res 293: $368-372$

Waldmann V, Wacker J, Deichmann M (2002) Absence of mutations in the pleckstrin homology $(\mathrm{PH})$ domain of protein kinase $\mathrm{B}(\mathrm{PKB} / \mathrm{Akt})$ in malignant melanoma. Melanoma Res 12: 45-50

Zhou XP, Gimm O, Hampel H, Niemann T, Walker MJ, Eng C (2000) Epigenetic PTEN silencing in malignant melanomas without PTEN mutation. Am J Pathol 157: $1123-1128$ 